\title{
Research on Forming Conditions and Constituent Subject of Creative Industry Cluster
}

\author{
Zongliang Zhang \\ School of Business of Linyi University, Shandong Linyi, 276000
}

Keywords: Culture; Creative industry cluster; Forming conditions; Constitute subject

\begin{abstract}
In recent years, culture and creative industry cluster issue have hot topics; the existing research is still immature. The formation mechanism of culture and creative industry cluster is particularly important. In this paper, for the study of culture and creative industry cluster, this based on the literature analysis. The basic concepts involved the culture and creative industry cluster to define, and reveal the characteristics and composition of culture and creative industry cluster.
\end{abstract}

\section{Research on the Formation and Evolution of Spatial Layout of Culture Creative Industry Cluster}

The concept of "cluster" involves three "space": economic space, geographical space, social space. Which is the basis of geographical space, economic space is a source of social space is the key.

Geographical Space is a tangible physical relationship, which consists of point, line, surface, body, etc. between geometry; Economic Space is invisible, is an abstract mathematical concept of space extending in the field of economics, It refers to a variety of economic relations between the elements of the economy. It is the location of economic phenomena and economic activity in certain geographical scope to the distribution, shape, size and form of the interaction is characterized by the existence and objective entity. Social space is invisible, can affect the relationship between social groups in which people strength spatial arrangement or distribution, social groups are perceived and utilized space, it's just a term population study. Geographical proximity is an important condition for cluster development.

Spatial agglomeration is the most prominent industrial clusters appearance characteristics. Near Space agglomeration constitute industrial cluster is a worldwide economic phenomenon. US high-tech companies such as Silicon Valley, is the gathering place, California is the entertainment industry gathering place, Madison Avenue in New York is the US advertising industry gathering place and so on. Similarly, the link between culture and creative space industry cluster is also based on abstract economic space in geospatial figurative. From the foregoing time dimension of cultural and creative industries cluster formation and evolution were analyzed to describe this section focuses on its geographical space dimension.

\section{Research on the Formation and Evolution of Time Gradient of Culture Creative Industry Cluster}

From the perspective of industrial economics, the focus of enterprises is the starting point for cluster formation. Business focus is simply the number of firms gather. When companies within the cluster around the industrial chain to implement specialization, showing a strong cluster effect and the formation of strong intrinsic association, feature integrated high agglomeration chain time, this gathering that has the characteristics of industrial clusters in the true sense. Thus, the formation and evolution of cultural and creative industry cluster with environmental change is a gradual and continuous process. Therefore, it is necessary from the perspective of the time gradient dynamic analysis of the cultural and creative industry cluster formation and evolution process.

The Definition of Formation and Evolution of Culture Creative Industry Cluster. Many scholars dynamic industrial cluster formation process is called "industry cluster life cycle." "Industry cluster life cycle" depicts the entire process from the formation of industrial clusters to recession. Since the impact of regional development environment, innate resources, market 
competition and technological progress, social development and policy change, industrial development and metastasis of internal and external factors, even under the influence of certain causal factors, the process of the formation and evolution of industrial clusters must have some life cycle forms.

Porter argued that the growth process can be divided into bud cluster, three stages of evolution and decline. Tichy G (1998) cluster life cycle is divided into the birth, growth, maturity and decline in four phases. Richard Ponder (1996) by means of intermittent equilibrium model, the industrial cluster evolution stage into production, convergence and re-adjustment. There are scholars transplant stage, into the group phase, the stabilization phase, and "three-stage" was. Wei Jiang (2003) cluster-based learning mode, the dynamic evolution of the spatial structure of the cluster is divided into: decentralized production system, the original competitive clusters, static efficiency clusters and clusters mature state. Looking perspective, these are the basic outlines of the evolution of industrial cluster formation characteristics. On the basis of the relevant literature and empirical research on the third chapter, this paper will form the cultural and creative industry clusters span to be divided, will stage its evolution into infancy, the growth of radiation, self-organization of the three stages of development. Three stages of development of cultural and creative industry clusters produce a formal sense.

The Characteristic of Formation and Evolution of Culture Creative Industry Cluster. Cultural and creative industry clusters and other tertiary industry clusters similar, and both belong to the economic clusters, therefore, their formation and evolution process has some common characteristics:

Emerging Industrial Clusters gathering period is the number of enterprises. When a large number of companies gathered in a particular area of production or operations, it produced "internal economies of scale" and "external economies of scale." "Internal economies of scale" from a single enterprise with the increase of production factor inputs, outputs the size of the increase, thereby decrease the cost per unit of product. It is to rationalize the use of resources by individual enterprises, organizations and scientific transformation efficiency is significantly improved and the economic.

"External economies of scale," the German economist Max Weber (1929) called "agglomeration economic effects." It is especially due to geographical concentration and lead to social division of labor deepening costs of setting up and utilization of regional resources among competing corporate relations brought about by the savings. "Agglomeration economies" effect produces a lot of "convenience": First, the convenience of proximity; such as proximity to markets, intermediate inputs, the convenience of complementary products, as well as close to the information and convenience of the public service; Second, enterprises newborn convenience; convenient elements of industrial clusters in similar enterprises generated so newcomers can integrate resources with less risk, lower cost of creating new enterprises; the third is innovative convenience; industrial cluster study convenience and face communication leading to "a cluster of air waft trade secrets" (Marshall, 1929).

Technology spillover effect makes knowledge is diffused, the cluster is more prone to innovation activities; Fourth, social capital formation and accumulation of convenience. The cluster due to the geographical proximity of actors, frequent exchanges, relatives and friends of Love and other factors are easily formed and accumulated good social capital. These two types of agglomeration economies effects are passive, industry cluster effect spontaneous, is the root cause of cultural and creative industries cluster formation.

The development of industrial clusters has its own power system in the process of formation and evolution in. The main driving force comes from demand-pull. Diversification of demand-pull development resources rational allocation within the region and a virtuous cycle, provide justification for the direction of flow of factors of production and specialization, changing the layout of the allocation of resources. "The demand determines industrial development" refers to "supply and promote", "technology push", "pull the division" has become the power source of industrial evolution. 
Demand trends in the ultimate performance on raw materials, technology and other industries platform, providing the market capacity for the professional division of refinement. Alan Scott noted, are subject to a variety of economic Engel quantitative and constraints. The level of development of basic economic and consumption directly determines the development of industrial clusters.

As the market economy inherent flaws and unbalanced regional economic development characteristics, select industrial clusters cannot simply rely on the optimal path to regulate the market system, and need to rely on market service system, technology development system, regional innovation networks and other major government support system support external system. The cluster formation process, cluster culture incubators, organizes incentive and restraint mechanisms constitute the industrial cluster governance mechanisms. Cluster internal value chain governance longitudinal and transverse external governance related industries constitute a cluster formation of external support system. This system can reduce the risk of cluster organizations, to provide the correct industrial policy guidance, supporting infrastructure and public service facilities, provide market regulation and supervision is the main guarantee of industrial cluster formation. At the same time, the formation of cultural and creative industry cluster also has its own characteristics.

\section{Research on the Formation and Evolution Path of Culture Creative Industry Cluster}

Based on the theory of time series and spatial layout of the above for the formation of cultural and creative industries cluster analysis and mathematical analysis, as well as cultural and creative industry clusters based on existing case studies, it can be summed up cultural and creative industry clusters form a track of generally "dot" "linear", the three stages of "mesh" evolving.

Point-Like Stage. In the process of formation of industrial clusters, the budding cultural and creative industry cluster must be on certain industries and leading companies gather initial operating inseparable. The emergence of these leading companies are industrial clusters can sprout premise. Cultural and creative industry clusters originally derived from some of the core business based on the unique cultural background, through the rational location choice and gradually gathered to certain areas. The initial embryonic stage of cultural and creative industry clusters from key corporate culture and creative industry chain and promote the joint development and maturation growth of other businesses and industries. Knowledge spillover mechanism and cooperative competition mechanism provides dynamic mechanism for their common development.

It appears clusters may be caused by technical and economic benefits of agglomeration, but also may be caused by accidental gathering events. Construction Thus, in this stage of development is often reflected in the cultural and creative industry chain of major cultural enterprises that focus on fostering cultural arts, film, music, traditional crafts and other traditional cultural enterprises. By creating the core business and competitive industries have a competitive advantage, for the formation of cultural and creative industry chain to lay the foundation and exemplary role.

Meanwhile, around the periphery of the core enterprise culture in the communication industry with its mature market network for local cultural consumption in creating an atmosphere and culture play a key role. Core class industry and ancillary industry support each other, to promote the extension of enterprises in the development and agglomeration. Regional spatial aggregation entities and their support cultural and creative industries in a specific area of the body being formed is the future of cultural and creative industries cluster initial "growth pole", these growth poles in the geographical space showing the cultural and creative industries "dotted" distribution; It is the first bud cluster formation.

Line-Like Stage. "Dot" after the distribution of cultural and creative industries into the core business specialization and collaborative development track, they are bound to carry out industrial chain extension and widening. Because consumption and dissemination characteristics of cultural industries, cultural and creative sectors intermittent aid of some form of cooperation together to form a series of cultural and creative industries reach ability chain. Creative ideas and licensing, production and equipment adjustment, creative product of reproduction, public distribution of 
creative products, creative products and other consumer-related activities and the cultural and creative industries constitute "cultural and creative industries production system." Participating companies in this industry chain by seeking overflow and transaction cost savings geographical proximity, knowledge and technology acquired Value itself. At this stage, the development of cultural and creative industry chain companies each node has a lateral extension of both bold and vertical features. The traditional cultural and creative enterprises in the development process will continue to draw new forms of economic development, the transformation from traditional content-oriented enterprises for the design-oriented enterprises, from production to marketing, business development type enterprise.

On the other hand, compared to other industries, cultural and creative industries more reflect the post-Faradism "flexible specialization," the division of labor. Such a division of the social network formation mechanisms and mutual learning mechanism has become an important mechanism for endogenous development of the industry. The intense radiation and high permeability characteristics of cultural and creative industries but also determine its elements between institutions and other related industries and there is a wide range of contacts. Then, the core class corporate culture and creative industries industrial chain, supporting enterprises, enterprises extend relatively stable division of labor based on upstream and downstream value chain network system constituted gathering space, brought to extend the industrial chain, which belongs to agglomeration economies The longitudinal extension of the geographical scope. Such "linear" development approach is the integration of regional cultural resources; improve the overall competitiveness of industry to go through the process.

Mesh-Like Stage. With the formation "linear" stage chain matures and regional industry environment, synergies and spillover effects of the cluster so that cultural and creative industries within the region gather to grow geometrically. Many small businesses similar properties concentrated in a particular place to generate internal economic effects of growing regional integration efforts so that the cultural and creative industry clusters can take advantage of its "radiation effect" and "path dependence" promotes peripheral layer and extending layer of cultural and creative industries chain formation. Longitudinally extending chain of industrial clusters and lateral node bold, strengthen each other and staggered, the whole system begins from the linear chain, to "mesh" network-based forms of development, and ultimately the formation of mesh type of cultural and creative industries cluster. Meanwhile, the net surface phase clusters can also break the division limit administrative areas. In the high-speed network technology developed today, with the multi-channel communication, knowledge, information, resources can flow freely and passed between areas. So it had to rely on the main urban culture, cross-administrative regions cultural and creative industries cluster development trend mesh. Also, because the sound and perfect the market economic system, the completeness of market and industry scale outside the operating mechanism to help the cultural and creative industry chain can break through a simple linear development path, the road of mesh-type cluster.

\section{References}

[1] Allen J.Scott. CREATIVE CITIES: CONCEPTUAL ISSUES AND POLICY QUESTIONS[J]. Journal of Urban Affairs. 2006 (1)

[2] Alexander Kaufmann,Franz T. dtling. Systems of Innovation in Traditional Industrial Regions: The Case of Styria in a Comparative Perspective [J]. Regional Studies. 2000 (1)

[3] Denis Maillat. Innovative milieux and new generations of regional policies [J]. Ent

[4] Florida Richard.The rise of the creative class:and how it's transforming work,leisure,community and everyday life. .2002 
[5] Thomas W. Paradis.CONCEPTUALIZING SMALL TOWNS AS URBAN PLACES: THE PROCESS OF DOWNTOWN REDEVELOPMENT IN GALENA, ILLINOIS. Urban Geography. 2000

[6] Andersson M,Karlsson C.Regional Innovation Systems in Small and Medium Sized Region. The Emerging Digital Economy. 2002 